\title{
Study on Construction of Practical Teaching System for Architectural Engineering Major
}

\author{
Zhiguo Huang \\ Chongqing Vocational Institute of Engineering, Chongqing ,470035, China
}

Keywords: Architectural engineering major, Practice, Teaching system

\begin{abstract}
Students of architectural engineering major in universities are required to have a strong practical operation ability, which requires that the education and teaching works of universities shall be practical and in place; among these works, the construction of practical teaching system for this major appears to be extremely important. This paper lists the basic characteristics of the practical teaching system for the architectural engineering major, analyzes the construction principles of the practical teaching system for the architectural engineering major, and puts forward the construction ideas of the practical teaching system for the architectural engineering major.
\end{abstract}

\section{Introduction}

The teaching objective of the architectural engineering major in universities is to cultivate graduates so that they grasp the basic theoretical knowledge and practical skills demanded for this major and possess work abilities and skills related to architectural engineering major. Moreover, graduates of architectural engineering major must also have the abilities in lifelong learning and continuous and in-depth development in the specialty. Only by this, graduates can engage in architectural technology or management work in different units in the construction industry. The writer suggests to implement the all-round reform on the construction of practical teaching system for the architectural engineering major, in order to really cultivate practical architectural engineering talents who meet the needs of employers in the society.

\section{Basic characteristics of practical teaching system for the architectural engineering major}

Under normal circumstances, according to the teaching characteristics of architectural engineering major, the practical teaching system of architectural engineering major can be mainly divided into demonstration and verification based practical teaching system, technological operation based practical teaching system, design based practical teaching system and integrated practical teaching system. Firstly, the demonstration and verification based practical teaching system mainly covers the basic mechanics test, structure test, and practical training on architecture cognition. Secondly, the technological operation based practical teaching system mainly covers the basic computer knowledge, general knowledge about architectural charting and drawing recognition, building material experiment, architectural CAD, practical survey training, etc. Thirdly, the design based practical teaching system is mainly to provide all-round and standardized design of different subjects for the architectural engineering major, such as the design of building construction, construction budget, construction organization, etc. The forth type is the integrated practical teaching system. For the construction of this first type of practical teaching system, attention is paid to cultivating the young university students' cognitive competence; the construction of the second type of practical teaching system focuses on improving students' abilities in practical operation, accepting new knowledge and skills as well as innovation; the third type of practical teaching system places emphasis on cultivating students' abilities in document retrieval and using relevant knowledge to solve specific problems; finally, the integrated practical teaching is to implement the all-round and in-depth inspection about students' comprehensive abilities. 


\section{Construction principles of practical teaching system for architectural engineering major}

The first principle is to set up and cultivate the dynamic object change, so as to the continuous updating of the education and teaching system. The cultivation objectives of practical teaching system for architectural engineering major in universities shall be subject to dynamic adjustment based on the progress of times, the development of science and technology and the needs of the market, so as to ensure that the cultivated talents can continuously adapt to the constantly changing market needs. From the microcosmic perspective, the main contents and teaching methods in the practical teaching system for architectural engineering major shall be subject to rational adjustment based on the changes in posts and first-tier production technologies. From the macroscopic perspective, the practical teaching system for architectural engineering major is an organic component for interrelation of different practice projects, thus it shall be subject to dynamic adjustment based on the changes in posts and employers' application technologies, so achieve the all-round optimization of practical teaching system for architectural engineering major, ensure that the practical teaching system can be kept in efficient and high-quality operation, and create first-class practical training conditions for young university students to grasp new vocational skills.

The second principle is to set up and cultivate the ability of technology application, to continuously meet the actual needs of the first-tier management. The Construction of the practical teaching system for the architectural engineering major shall start from the concrete situation, to have a in-depth discussion about the interrelation among knowledge, ability and quality. It is required to insist on strengthening the mainstream of technology application ability, so as to strengthen the cultivation of new-type practical teaching system dominated by first-tier production management ability. Besides, it is also required to focus on the key points, place emphasis on features and develop a new-type teaching mode with university-enterprise cooperation and close production-teaching combination, to make the practical teaching system for architectural engineering major closer to the actual requirements on first-tier production management and post skills, and then practically improve the quality of higher education and make learners really become special application-oriented talents of higher education with the characteristics of times.

The third principle is to set up the practical training environment simulation for the architectural engineering major. The practical training programs for architectural engineering major shall be forward-looking. In the process of constructing the practical teaching system, it is required to fully consider the fact that the practical training base shall create a working environment that meets enterprises' actual environment. A corresponding relationship shall be kept between practical training programs and vocational posts and the pre-employment system shall be implemented to achieve the real practice and solid work; besides, the seamless connection shall be provided for students, namely there shall be no or only a very short adaptation period. Meanwhile, the practical training environment for architectural engineering major shall also more comprehensively simulate employers' most real environment; for example, the training site arrangement, equipment allocation, training operation standard, architectural production identification and many other contents shall be furthest kept consistent with the enterprises' actual production environment, in order to make university students of architectural engineering major feel like staying in the real vocational post environment during the practical training, and consequently constantly stimulate their motivation of grasping the professional skills. In view of the rapid development and application of modern scientific and technological achievements, the time interval from the initial scientific discovery to the large-scale application becomes increasingly shorter, leading to the faster elimination of technologies and products; therefore, it is required to rationally consider the forward-looking setting of teaching contents for architectural engineering major in the process of implementing the dynamic practical teaching programs, so as to rapidly update the equipment for practical training operation by learners; the training modes and methods shall be also subject to dynamic adjustment based on the constantly changing environment. 


\section{Construction ideas of practical teaching system for architectural engineering major}

\section{Establishing and improving the framework of practical teaching system for architectural engineering major}

The practical teaching system for architectural engineering major can be divided into four interrelated constituent parts: cognition practice, teaching practice, off-campus teaching and post practice, so as to thoroughly change the inherent theory-oriented cultivation mode. Firstly, implement the cognition practice, mainly including the understanding of architectural construction drawings and learning by observation at the construction site, etc., so as to practically understand the application of construction material related standards and architectural construction drawings as well as quality control, improve university students' perceptual cognition ability, make them learn courses of the architectural engineering major in a better way and have a better understanding of key learning points in subsequent major courses. Secondly, implement the teaching practice, which is mainly based on relevant requirements of practice outline and instructions. It is required to practically train different important abilities in a more comprehensive and in-depth way by means of learning the drawing plotting, trying the architectural construction design, implementing architectural surveying practice and architectural engineering budget and settlement simulation, etc. In the evaluation process, try to integrate with enterprises' actual environment, and positively employee those personnel with rich practical experience in enterprises, especially those senior technicians and technical leaders, to take part in the trainee evaluation. Where the conditions permit, it is also feasible to establish the graduate evaluation committee in which enterprises take part, and inspect learners' practical abilities with employers' employment standards. Thirdly, implement the off-campus practice to strive for improving university students' different abilities by means of all-round cooperation with employers and those enterprises and public institutions with whom the training agreement is signed. Internship units shall be required to arrange stable training instructors, and universities shall implement all-round training tracks, so as to grasp interns' trends and their condition of mastering new knowledge and skills. Leading university teachers shall also make a comprehensive summary to work out the gap between universities' requirements and employers' actual standards, and consequently provide convenience for universities to rationally adjust the corresponding teaching arrangement, course design, means of education, etc., and make the practice more perfect feasible. Fourthly, implement the post practice, which is one of the main links for improving interns' comprehensive quality. It is required to face to different student groups and require them to take posts in internship units and complete certain tasks based on their future development directions, and return to their universities with practical training achievements; besides, it is also required to assign special personnel to guide them, so as to lay a good foundation for their graduation design.

Practically improving the contents of practical teaching system for architectural engineering major

Firstly, strengthen the practical training on basic skills. It is achieved mainly by applying class training on theoretical courses, the site visit, observation and simulated demonstration, and practical operation in the practical teaching link and many other methods as well as different forms such as multimedia courseware teaching, so as to realize the objectives of practical trainings for architectural engineering major. Secondly, lay emphasis on interrelation between general abilities and professional skills. The training on general abilities and professional skills shall be completed based on applying the practical class training provided during their school days. Among a lot of links of the practical teaching, there shall be not only the professional skills that can adapt to the needs of students' future post groups, but also other professional skills related abilities, such as abilities to collect and dispose various information, and learn and capture new knowledge and skills, as well as abilities in practical computer application, teamwork, social activity organization and planning, etc. It is required to lay emphasis on training of basic abilities for architectural engineering major, and practically grasp the theoretical knowledge and relevant skills according to the main skills required by the professional qualification certificates. Thirdly, strengthen the cultivation of professional core abilities and comprehensive quality. Core abilities required by architectural engineering major in universities 
include the abilities in carrying out architectural engineering management and practical technology application. It is required to carry out it from shallow to deep level on the basis of practice, which is completed mainly by university students' post practice and participation in simulated architectural construction, etc. In the specific process of implementation, it is required to emphasize the seamless connection between important abilities and comprehensive quality. Fourthly, strengthen the sufficient connection between working process and learning process. Working process shall be a complete working process implemented by enterprises to complete a certain work and obtain working achievements. As for the practical teaching system for architectural engineering major in universities, it is required to carry out typical tasks based on posts and post groups corresponding to this major, and divide them into different learning fields and scenes according to professional characteristics, so as to complete the practical teaching tasks for this major.

\section{Vigorously strengthening the practical teaching base and teacher group construction for architectural engineering major}

Firstly, construct the in-campus practical training base jointly by teachers and students for the architectural engineering major. It can be said that the in-campus practical training base construction is the important guarantee for implementing the practical teaching reform. It is required to positively organize teachers and students of this major to implement the self-design and construction on the basis of in-campus practical training base for architectural engineering major, so as to establish the architectural engineering major training center that can accommodate learners of relevant majors to receive the construction skill trainings, to achieve the organic connection with relevant practice sites for this major, such as building material training center, civil engineering training center, architectural CAD training center and construction cost training center, and to really provide modern students of architectural engineering major with the in-campus training base that has complete functions and facilities and is in the leading level within the city. Secondly, utilize the university-enterprise cooperation to strengthen the off-campus practical training base construction for architectural engineering major. It can be said that off-campus base is one of the important contents in the university training system, because constructing the off-campus training base can effectively cover the shortage of in-campus base in the aspects of site, equipment and facilities, etc., so as to provide a more real training environment for the architectural engineering major. Meanwhile, it can also improve university students' employment competitiveness and effectively shorten their work adaptation period. Based on the off-campus training base, students of architectural engineering major can have an in-depth learning, practically realize the real working atmosphere in modern enterprises, more quickly get familiarized with and even proficient in the most advanced equipment, technology and technological process in the architectural engineering industry, grasp the skills and technologies required for different posts within the shortest time, and obtain favorable practice and working experience; meanwhile, it can also provide university students with a good carrier to improve their vocational quality, occupational ethics and spirit of teamwork. Thirdly, speed up the progress of training teacher group construction. It can be said that the cultivation of teacher talents is the important basic content of practical teaching for architectural engineering major. Considering the continuous and in-depth improvement of modern teaching mode, universities shall continuously strengthen the vigorous cultivation of "double-qualified" teaching talents on the basis of university-enterprise cooperation. It is possible to not only arrange teachers to participate in training and further education on a planned and organized basis, but also arrange teachers of major courses to periodically engage in practice in cooperative enterprises, so as to effectively improve their professional skills by means of practice through taking a temporary post, etc. On this basis, universities may also consider introducing high-quality and highly skilled engineering technicians from first-class enterprises in the architectural industry to give lessons or lectures. If the condition permits, it is also feasible to employee professional engineering technicians to take the posts of full-time training instructors for this major, so as to quickly enhance the practical teaching strength for this major. 


\section{Conclusion}

To sum up, constructing the practical teaching system has become an important means of cultivating the practical operative ability of modern graduates majoring in architectural engineering in our universities. Therefore, during the practical teaching for architectural engineering major, it is required to promote the practical teaching system reform in a continuous and in-depth way on the basis of improving students' comprehensive quality, which is also one of the key contents for teachers of architectural engineering major in universities to carry out the study on practical teaching system; meanwhile, it is very important to guarantee that university students can obtain the solid practical ability.

\section{References}

[1] Dai Yimin. Study on Internship and Practice Teaching Cultivation Mode for Architectural Engineering Major. Education for Chinese After-school, 2013 (12).

[2] Yu Li. Initial Research on Practical Teaching Reform of Architectural Engineering Major in Higher Vocational Colleges. Education Teaching Forum, 2013 (20).

[3] Xiang Yong and Ye Chaoyang. Study on Practical Teaching Reform of Architectural Engineering Major Relying on Academic Competition. Doors and Windows, 2014 (11).

[4] Shi Yayong. Research on Practical Teacher Group Construction for Architectural Engineering Major. Contemporary Vocational Education, 2015 (1).

[5] Tang Chunping and Liu Jian. Construction of Practical Teaching Quality Evaluation System for Architectural Engineering Major in Higher Vocational Colleges. Journal of Jiamusi Vocational College, 2015 (3). 